\title{
Administração, OMS e Covid-19: uma Relação Conflitiva
}

\section{Administration, WHO, and Covid-19: a conflicting relationship}

\author{
Reginaldo Soura Santos ${ }^{1}$ \\ Emerson de Sousa Silva ${ }^{2}$ \\ Elizabeth Matos Ribeiro ${ }^{3}$ \\ Elinaldo Leal Santos ${ }^{4}$ \\ Carolina Chagas Martins ${ }^{5}$
}

\begin{abstract}
Resumo: Este texto é resultado de um trabalho de natureza exploratória que visa analisar os aspectos administrativos que estão sendo empregados para a interpretação e resolução dos impactos causados pela pandemia da Covid-19. Para cumprir esse objetivo, a discussão proposta se fundamentou nas bases teórico-metodológicas da administração política, considerando-a ser um campo de conhecimento mais apropriado para interpretar os fatos e atos que dão expressão e sentido às relações sociais, particularmente as produção e distribuição. Como base empírica, o estudo foi estruturado para realizar uma discussão sustentada em uma 'trilogia', considerando três dimensões geoespaciais de análise principais: a OMS, objeto deste primeiro ensaio; o comportamento dos países desenvolvidos, com destaque para os EUA, alguns países europeus, China e Japão; e concluindo com a análise das singularidades brasileiras. Como resultado desse primeiro exercício sobre a concepção do padrão de administração assumido pela OMS, foi possível concluir que os acertos e erros na gestão da Pandemia da Covid-19, em âmbito global, são definidores dos sucessos e fracassos dos processos de intervenções que têm por finalidade última solucionar ou ao menos mitigar os problemas sociais. Nesse sentido, considera-se que o retardo das ações por parte da OMS, especialmente no que se refere à decisão declaratória da situação de emergência elevou enormemente os custos para as nações e para a economia global.
\end{abstract}

Palavras-chave: Pandemia de Covid-19. OMS. Administração Política.

\footnotetext{
1 Professor Visitante da Universidade Federal de Alagoas (UFAL) e do Programa de Pós-Graduação em Administração da Universidade Federal da Bahia (UFBA).

2 Doutor em Administração/NPGA-UFBA, da Universidade Federal de Sergipe-UFS.

3 Professora da Universidade Federal da Bahia / Escola de Administração (EAUFBA)

4 Doutor em Administração/NPGA-UFBA, Professor Adjunto da Universidade Estadual do Sudoeste da Bahia (UESB)

5 Cirurgiã-Dentista, formada pela Escola Bahiana de Medicina e Saúde Pública, atualmente cursando Improving Global Health: Focusing on Quality and Safety-Harvard University.
} 


\begin{abstract}
This text is the result of an exploratory work aiming to analyze the administrative aspects that are being used for the interpretation and resolution of the impacts caused by the Covid-19 Pandemic. The proposed discussion was based on the theoretical and methodological bases of political administration, considering it to be a more appropriate field of knowledge to interpret the facts and acts that give expression and meaning to social relations, mainly production and distribution. As an empirical basis, the study was structured to carry out a discussion based on a 'trilogy,' considering three main geospatial dimensions of analysis: WHO, an object of this first article; the behavior of developed countries, with emphasis on the USA, some European countries, China and Japan, and concluding with the analysis of Brazilian singularities. As a result of this first exercise on the design of the administration standard assumed by WHO, it was possible to conclude that the successes and errors in the management of the Covid-19 pandemic, globally, are defining the successes and failures of the intervention processes that aim to ultimate purpose to solve or at least mitigate social problems. WHO's inactions, especially about the emergency's declaratory decision, have increased the nation's costs and costs of the global economy.
\end{abstract}

Keywords: Covid-19. WHO. Political Administration.

\title{
1. Introdução
}

1.1. Invariavelmente, os trabalhos de avaliação de eventos dessa natureza sempre tomam como eixos relevantes aqueles aspectos ligados diretamente à pandemia (como a zoonose, a farmácia e a clínica médica) e aos efeitos mais evidentes do ponto de vista da economia (como os custos - estatais e privados - envolvidos na cura, os impactos negativos no nível de atividades, principalmente no de emprego, etc.). Porém, quanto à forma como o evento ou as medidas para solucioná-lo foram ou estão sendo administradas pouco se investiga; temos apenas indicações e notícias gerais a respeito da estratégia adotada e os atores envolvidos - o que significa não ir muito além dos aspectos jurídico-institucionais. Isto é o que superficialmente chamam de 'gestão da pandemia'.

Indaga-se então: a estratégia foi a mais correta?; está compatível com a finalidade da ação pública para o combate ao problema?; os custos envolvidos estão compatíveis com os resultados alcançados?; as medidas de combate à pandemia foram tomadas no tempo mais adequado ou houve negligência?; como tem ocorrido o gerenciamento das ações, desde a opção de financiamento das melhores linhas de pesquisa, passando pela testagem dos remédios, até chegar à estruturação e coordenação das ações nas enfermarias, lugar mais sensível no enfrentamento do problema?; com os recursos disponíveis, seria possível fazer uma administração melhor da crise a ponto de diminuir o impacto em termos de vítimas fatais?; nas circunstâncias estruturais das economias capitalistas (de desemprego estrutural aberto e ampla miséria), a forma de recuperação 
econômica, dando mais ênfase ao consumo (transferência monetária direta a indivíduos e famílias), em detrimento da produção (sustentação dos negócios das micros, pequenas e médias empresas e recuperação e/ou expansão da produção de uma infraestrutura que se mostra inadequada ou insuficiente em quase todos os países) foi ou está sendo a mais correta? Essas questões, entre outras que poderiam ser acrescentadas, dizem respeito a conteúdos eminentemente ligados ao campo da administração, cuja desatenção pode realmente transformar um vírus que deveria ficar circunscrito à região de sua zoonose em uma pandemia de caráter mundial, de elevados e incalculáveis custos clínicos, psicológicos e materiais. Desse modo, o propósito da análise proposta nesse conjunto de textos que irão conformar uma 'trilogia' sobre o tema é justamente chamar a atenção da academia e dos profissionais que atuam neste campo para o fato de que a questão administrativa é central nas estratégicas para o enfrentamento, seja de uma pandemia dessa natureza ou qualquer outro processo social de ampla magnitude. $\mathrm{O}$ que implica reconhecer que as análises e ações prioritárias não podem ficar subsumidas em aspectos clínicos ou econômicos. É fundamental colocar em evidência o papel central que os fenômenos administrativos têm como recurso teórico e técnico para direcionar soluções para as crises sociais, econômicas, políticas e culturais.

Para dar conta das complexas dimensões que a crise provocada pela Pandemia da Covid19 tem impactado, decidiu-se desenvolver este estudo exploratório por meio de uma trilogia que envolverá a produção de três artigos complementares. Este primeiro fará uma análise preliminar sobre os impactos das decisões administrativas tomadas pela Organização Mundial de Saúde (OMS) para orientar as nações no combate ao novo vírus. O segundo tratará dos comportamentos diferenciados assumidos por alguns países desenvolvidos destacando o papel dos Estados Unidos da América do Norte, de alguns países Europeus, do Japão e da China. Por último, será desenvolvido o último artigo que concluirá essa tríade que abordará as singularidades dos padrões de administração (ou sua ausência) assumidos pelo governo brasileiro.

1.2. Muito embora o termo "pandemia", em muitos lugares do planeta, remeta a contextos medievais, esse tem sido um fenômeno bastante presente nas sociedades contemporâneas, não sendo raros os casos de eclosões de riscos sanitários, desde o início do século XX e que tem se perdurado no século atual. Se o passado foi moldado por ocorrências pandêmicas, o futuro da humanidade ainda não está livre desse fenômeno e, por muitas décadas, esses riscos ainda assombrarão a humanidade nas suas mais diversas formas e lugares (SANDS, 2017).

Nos últimos cem anos, podem ser listados ao menos sete eventos dessa natureza e com potencial elevado de riscos locais e globais:a Influenza A (H1N1), a Gripe Espanhola,1918; a 
Síndrome Pulmonar por Hantavírus (HPS), nos Estados Unidos, em 1993; a Síndrome Respiratória Aguda Grave (SARS-CoV), na China, em 2002; a Influenza A (H5N1), também na China, em 2004; a Síndrome Respiratória do Oriente Médio (MERS-CoV), na Arábia Saudita, em 2012; a Influenza A (H1N1) nos Estados Unidos, em 2009; o Ebola vírus (EVD), na República Democrática do Congo, no Zaire, em 2013․ ${ }^{6}$ Esse conjunto de evidências revela, portanto, que há muito tempo as endemias e os riscos de pandemias são uma realidade para as sociedades contemporâneas; e, por essa razão, não se justifica mais a fragilidade de padrões de administração mais efetivos para o controle desses fenômenos

Sendo essa uma realidade concreta a ameaçar toda a humanidade, desde o início do século $\mathrm{XX}$, cabe indagar: porque seu enfrentamento tem sido negligenciado até os dias atuais? Talvez uma resposta possível seja encontrada nos estudos desenvolvidos pela administração política e em outros estudos críticos, incluindo as contribuições mais próprias dos estudos organizacionais e da economia política, que denunciam as incompatibilidades entre o ideário (neo)liberal e as soluções coletivas que esses fenômenos demandam.

Os fracassos ou descasos dos governos nacionais e agências multilaterais para encontrar soluções administrativas dirigidas para encaminhar saídas coletivas para um problema que aflige toda a humanidade explicam os desafios e a falta de perspectivas efetivas para o enfrentamento da Pandemia atual. Considera-se, pois, que a insistência dos sistemas políticos e socioeconômicos globais e nacionais de priorizar formas individuais para resolver os problemas coletivos contribuem, ainda mais, para seu aprofundamento. No caso da atual crise sanitária, o próprio meio de propagação individual do vírus limita essa alternativa utilitária, tendo em vista a necessidade de definir limitações dos níveis de interação social como recurso imediato para frear sua expansão.

Logo, como os surtos pandêmicos exigem um combate coletivamente articulado, revelam-se como eventos sociais mais com forte conteúdo de natureza administrativa suscetíveis, portanto, a ações de planejamento, comando, coordenação, controle e organização que vão requerer abordagens sistemáticas que envolvem processos articulados de intervenções políticas (gestão, administração política) e técnicas (gerenciamento, administração profissional). Com esse argumento, defende-se neste texto que é essencial aos governantes, aos acadêmicos e demais atores sociais assumir que as pandemias são eventos afetos aos padrões de gestão das

\footnotetext{
${ }^{6}$ Frise-se que o surgimento de pandemias zoonóticas - aquelas que primordialmente se dão por meio da interação entre seres humanos e animais - vem, com o passar dos tempos, agudizando as suas características socioeconômicas, haja vista a expansão de transações produtivas que envolvem a caça de animais selvagens ou a criação de animais domésticos ou destinados à alimentação humana, além do aumento do tráfico (legal ou ilegal) de espécimes exóticos, sem esquecer a devastação das florestas tropicais (PIKE et al., 2010).
} 
relações sociais de produção, circulação e distribuição, ensejando, desse modo, a hipótese que são também objeto de estudo do campo da administração política ${ }^{7}$.

No presente artigo - que possui um caráter exploratório, descritivo e especulativo -, o objeto principal é sumarizar, à luz do campo de estudos e de ação da administração, a conduta da OMS diante da crise sanitária internacional causada pelo Sars-CoV-2, conhecida como Covid-19. Para tanto, a análise percorre os passos elaborados e sistematizados em um compêndio das medidas e atitudes de combate ao novo vírus assumidas pela referida organização, que vão desde a comunicação dos primeiros casos no mundo, registrados no réveillon de 2020, até a declaração de suspensão de repasses ao órgão feita pela presidência dos Estados Unidos da América (EUA), em junho do referido ano.

$\mathrm{O}$ artigo está estruturado em quatro seções, integrando esta introdução. $\mathrm{Na}$ segunda seção, serão apresentados os referenciais analíticos da administração política que darão suporte teórico ao estudo. Na terceira seção, são analisadas as decisões e desempenho da OMS na gestão da atual Pandemia. E, nas considerações finais, são apontados os avanços que o estudo trouxe e indicativo dos passos seguintes no aprofundamento das outras duas dimensões de análise que configuram a trilogia proposta.

\section{Suportes Analíticos da Administração Política}

\subsection{Referenciais analíticos da gestão de pandemias}

A literatura a respeito de como enfrentar e resolver o problema das pandemias tem sido relativamente abundante, tanto na definição técnica do que venha a ser e o que caracteriza e diferencia uma epidemia ou pandemia da outra, quanto no estabelecimento das diferenciações entre vírus, seus efeitos relativos à taxa de mortalidade e à desestruturação social, principalmente nos aspectos, econômicos, sociológicos e psicológicos. Do ponto de vista técnico, uma pandemia é definida como um surto em larga escala de uma doença infectocontagiosa que redunda na expansão dos níveis de morbidade e de mortalidade em um amplo espaço geográfico e que é acompanhado por desarranjos econômicos, sociais e políticos.

Segundo Qiu et al. (2017), são necessários os seguintes predicados para se caracterizar uma pandemia: ampla extensão geográfica, deslocamento espacial sistemático, feitio de novidade

\footnotetext{
${ }^{7}$ Segundo Santos (2004), Administração Política é o campo científico da ciência da administração que tem por objetivo estudar e compreender como as sociedades "gestionam" as suas relações sociais de produção com o fito de aprimorar os seus níveis de desenvolvimento e seus padrões de bem-estar, tomando como parâmetro toda a interação entre Sociedade e Estado e essa interação com a base produtiva que dá consequência operativa ao desiderato material.
} 
(de apresentação ou de vetor de disseminação), alta severidade (elevado índice de mortalidade), altas taxas de explosão e de expansão, pequenos níveis de imunização populacional e, principalmente, infecciosidade e contagiosidade. Da justaposição dessas dimensões, tem-se que pandemias são fenômenos multifacetados que articulam as mais variadas áreas da vida cotidiana, desde o uso do espaço geográfico até às formas de convívio social, passando pela qualidade dos próprios sistemas de transporte e de saúde.

Contudo, dada a facilidade com que elas transpõem fronteiras, a intensificação da integração dos mercados mundiais passou a atribuir outra característica às pandemias: a possibilidade de ameaçar e desestabilizar mundialmente os circuitos produtivos de forma mais aguda. Um dos desafios apresentados pelas pandemias é que, quase sempre, elas são causadas por cepas desconhecidas, o que redunda num limitado estoque de respostas para a previsão e para o controle de sua própria evolução (ABEYSINGHE, 2019).

Vale ressaltar que, a despeito da existência da OMS, não se pode afirmar que o planeta dispõe de um sistema integrado de vigilância para monitorar emergências de saúde globais, sejam de caráter zoonótico ou não (PIKE et al., 2010). Isso é curioso porque a eclosão de surtos e pandemias tanto se mostra um problema de saúde, tendo em vista os seus efeitos sobre as taxas de morbidade e de mortalidade, como também afeta o sistema produtivo e a tessitura social como um todo (QIU et al., 2017).

Essa análise não implica considerar que a transferência zoonótica seja um processo simples, trivial e corriqueiro, mas o aumento das interações entre humanos e animais - que se exponenciaram desde a Revolução Industrial - em combinação com o crescimento das densidades demográficas que ampliam as possibilidades de pandemias. A rápida expansão da urbanização, o aumento da velocidade e dos destinos de deslocamentos e os efeitos das mudanças climáticas figuram entre as principais variáveis explicativas para o aumento da recorrência de surtos epidêmicos e pandêmicos. Ademais, conforme já dito, surtos pandêmicos não são apenas uma questão de saúde. Quando do seu aparecimento, toda uma trama de relações mostra-se em sério risco de comprometimento e de iminente colapso, apesar de todo o desenvolvimento tecnológico experimentado pelas sociedades modernas.

Bird e Mazet (2018) reforçam esse ponto de vista quando declaram que apenas os aspectos tecnológicos de prevenção e combate às manifestações zoonóticas são insuficientes se não vierem acompanhados de estruturas consolidadas de vigilância, sistemas laboratoriais preparados, fontes adequadas e sustentáveis de financiamento, programas contínuos de treinamento e efetiva cooperação nacional e internacional. 
Qiu et al. (2017) não se furtam em repisar que pandemias são um elemento desestabilizador, posto gerarem prejuízos econômicos e dificuldades na administração dos processos sociais, dados pelos custos diretos e indiretos de enfrentamento da doença que são formados pela perda da capacidade produtiva (humana e material), sociais e psicológicas, por conta das medidas de paralisação de atividades e de distanciamento social necessárias para se deter o avanço do contágio.

Consequentemente, a mitigação de riscos de pandemias passa pela promoção de políticas públicas de Saúde, principalmente aquelas vinculadas à educação e à modificação de condutas e procedimentos. Não há como se combater tais eventos sob a exclusiva regulação privada das transações entre os agentes e circunscritas no âmbito de cada nação per si. Muito dos esforços de preparação e efetivação do combate a pandemias estão expostos aos mais diversos formatos de falha de mercados, de bens comuns até assimetrias de informações, o que pode resultar em ineficiências sociais elevadas.

Um bom exemplo desse fato é o processo de elaboração de uma vacina, situação que requer altos níveis de inversões, grande probabilidade de insucesso e de retorno relativamente demorado. Sem considerar o fato de que, dada a concentração de mercado do setor farmacêutico, os possíveis preços de acesso à medicação poderiam ser impraticáveis para a maioria da população alvo.

Como já ressaltado anteriormente, além dos impactos causados em outros campos, mesmo que uma ou mais nações por si tenham condições técnicas e econômicas de enfrentar uma pandemia, dado esse carácter de transnacionalidade, o evento pandêmico exige uma coordenação internacional (portando, uma Administração Política global) como forma de encurtar o tempo de "cura" do surto e diminuir os impactos negativos de seus efeitos. Seria muito custoso e de resultados incertos montar uma estrutura com essas possibilidades a cada momento pandêmico. Por essa razão, a necessidade de uma organização estatal multilateral com o objetivo de fazer a administração política da saúde em escala global fez nascer, já em 1946, no âmbito da Organização das Nações Unidas (ONU), a Organização Mundial da Saúde (OMS). Embora haja um reconhecimento universal da sua necessidade e do caráter imprescindível do seu trabalho desenvolvido, até aqui, a OMS fica muita exposta e próxima de severas críticas, como está correndo agora no tratamento da Covid-19. 


\section{Análise das Ações Iniciais de Administração do Combate à Pandemia pela OMS}

\subsection{Os determinantes do planejamento e da intervenção}

No manual da OMS, está dito que o planejamento de enfrentamento de pandemias deve ter por objetivo a identificação de ocorrências e a minimização dos seus efeitos de um modo que seja possível reduzir sua velocidade de transmissão, arrefecer o total de casos, diminuir as taxas de morbidade e de mortalidade, manter o funcionamento dos serviços essenciais e minorar os impactos socioeconômicos (WHO, 2005). Isso requer, por sua vez, um nível de coordenação que está além da área interventiva peculiar dos agentes econômicos (públicos e privados) e exige uma integração gestionária mais ampla por parte dessas entidades, o que este texto qualifica como bases próprias de uma Administração Política.

Ao analisar as ações coordenadas pela OMS com relação à pandemia atual, logo nos primeiros dias de 2020, observa-se que a Organização informou ao mundo que a China comunicara, a menos de uma semana, a ocorrência de alguns casos de pneumonia, cuja etiologia era desconhecida e que tinha acometido 44 pacientes na cidade de Wuhan, na província de Hubei (WHO, 2020a), o que permite considerar que a OMS ao ser notificada colocou em andamento uma série de medidas de acompanhamento do surto - corporificada pelo IMST (Incident Management Support Team) -, nos seus vários níveis de atuação, de modo a melhor administrar a evolução do quadro que emergia (WHO, 2020b).

Em seus primeiros pronunciamentos sobre a doença, a Organização focava na avaliação dos riscos e no alerta da comunidade mundial sobre as possíveis extensões do problema; além disso, repassava as informações recebidas da China sobre o status dos pacientes e a resposta da saúde pública relativa ao conjunto de casos de pneumonia em Wuhan (WHO, 2020a).

Baseando-se nas experiências pregressas como a Síndrome Respiratória Aguda Grave (SARS), identificada em 2003, e a Síndrome Respiratória do Oriente Médio (MERS), descoberta em 2012, ambas causadas por modalidades específicas de coronavírus, a OMS lançou para a comunidade internacional um conjunto-guia de procedimentos relativos às formas de detecção e testagem, bem como orientações de gerenciar eventos, tanto potenciais quanto efetivos (WHO, 2020b).Contudo, já existem estudos que mostram que a Covid-19 deveria ter sido tratada com maiores níveis de cuidados por conta do elevado número básico de reprodução - entendido como uma medida da velocidade de propagação - quando comparado com os outros comportamentos dos vírus anteriores (LANA et al., 2020). 
De todo o modo, por aquela mesma época, uma das principais preocupações da OMS era a de determinar a possibilidade da transmissão entre humanos e como ela se daria - foi quando apareceu o primeiro caso de Covid-19 fora da China, sendo o contaminado um cidadão tailandês, que retornara de Wuhan dias antes. Essa descoberta confirmou uma das expectativas da OMS e a levou a reforçar os alertas sobre as medidas de detecção, preparação e controle do avanço da nova moléstia (WHO, 2020).

Em janeiro de 2020, com base no Regulamento Sanitário Internacional (RSI), a Organização, ao tempo em que declarava que havia fortes indícios da transmissão entre humanos da Covid-19, convocou um Comitê de Emergência (CE) para avaliar a possibilidade de declaração de uma "Public Health Emergency of International Concern" - PHEIC como é mais conhecida. Porém, os membros independentes dessa instância administrativa alegaram que os dados disponíveis ainda eram incipientes para tanto e pediram mais dez dias de prazo (WHO, 2020).

A análise desses passos é importante porque a OMS, conforme indicado pelo RSI, somente após manifestação do Comitê de Emergência, pôde estabelecer uma PHEIC, na qual se reconhece uma situação de risco - incomum e inesperado - de disseminação, através de fronteiras de uma determinada doença contagiosa que vai requerer ações internacionalmente coordenadas (WHO, 2005a). Na vigência de uma PHEIC, a OMS passa, de modo integrado, a envidar esforços em nível global para auxiliar no controle da disseminação da enfermidade enfrentada nos países de ocorrência e de aconselhamento sobre monitoramento e prevenção às nações que ainda não apresentaram casos. Mas essa deliberação ocorreu somente no fim do mês de janeiro. Essa decisão de postergar a intervenção pode ter sido fatal para a sucessão de erros que vai ocorrer nas diferentes nações do mundo.

De modo concomitante, em relatório situacional de 30 de janeiro, a OMS apresentava um cenário no qual 7.818 casos da Covid-19 já haviam sido confirmados em 18 países - sendo 98,9\% na China -, distribuídos em quatro áreas distintas do globo (Ásia, Europa, Oceania e América do Norte), com um total de 170 óbitos, e o volume de risco global da doença sendo classificado como "Alto" (WHO, 2020c). No mesmo documento, a organização deixa claro que seu foco estava na qualidade e velocidade dos procedimentos de detecção laboratorial do novo coronavírus e que sua conduta se daria no sentido de garantir a capacidade de diagnósticos, a partir de três medidas principais (IDEM, 2020c): 
i. Construção de uma rede de laboratórios especializados de referência com experiência comprovada em detecção de coronavírus, que se prestariam aos laboratórios nacionais para confirmar os casos de Covid-19;

ii. Fortalecimento da capacidade nacional de detecção da Covid-19 para que testes de diagnóstico pudessem ser realizados rapidamente, sem a necessidade de envio para o exterior;

iii. Garantia da ampliação das disponibilidades de teste através da triagem dos protocolos de validação de dados de investigação laboratorial (limites de detecção, especificidade, etc.), do alinhamento sequencial de testes comerciais de coronavírus estabelecidos (por exemplo, SARS) para verificar se é provável que algum seja capaz de detectar a Covid-19 com alta sensibilidade e a aproximação das agências comerciais e não comerciais com capacidade para fabricar e distribuir testes PCR para a Covid-19, recentemente desenvolvidos.

Logo se vê que, nos primeiros dias, a preocupação da OMS era com a capacidade de testagem contra o novo coronavírus, para o campo clínico do problema; inclusive, mais adiante, passou a adotar medidas de vigilância e de preparação e resposta, principalmente nos países atingidos pela doença (WHO, 2020c).

$\mathrm{Na}$ segunda quinzena de fevereiro de 2020, patrocinou uma missão à China com a participação de diversos especialistas das mais variadas nacionalidades que visitaram Beijing, Wuhan e mais duas outras cidades com o objetivo de compreender o desenvolvimento da pandemia e, assim, subsidiar medidas a serem tomadas tanto por países que já enfrentavam o problema quanto aqueles que para ela se preparavam (OMS, 2020).

No entanto, foi somente em meados do mês de março de 2020 que a OMS se declarou preocupada com os alarmantes níveis de contaminação e de severidade da Covid-19 e com aquilo que ela chamou de inação, caracterizando a nova doença como uma pandemia. Muito tarde! Nesse mesmo dia, 11 de março, o mundo contabilizava 7.316 novos casos de Covid-19, formalizando um total de 126.335 contaminados, desde a eclosão da crise sanitária, e tendo vitimado 4.627 pessoas, mundo a fora (WORLDOMETER, 2020).

Ressalte-se que a OMS é uma agência multilateral sem autoridade para ditar procedimentos aos estados membros que a compõem, cabendo a ela tão somente coordenar ações de respostas a eventos patológicos e monitorar esses riscos, podendo ainda incentivar a promoção de medidas de melhora dos quadros de saúde em nível global. Todavia, isso não tem 
sido suficiente para mantê-la livre de críticas, principalmente quando for constatado que houve erro temporal na administração do problema da Covid-19.

\subsection{As críticas à administração da OMS}

A OMS é fruto de uma visão comunitária e agregativa que encara os mais diversos problemas enfrentados pelas nações - dentre esses o risco à saúde -, como algo passível de um tratamento coordenado e administrativamente partilhado (KAMRADT-SCOTT, 2015).Todavia, de acordo com Ventura e Perez (2014), trata-se de uma entidade bastante suscetível a críticas, polêmicas e contestações, sendo um campo fértil para conflitos e controvérsias. Essas objeções, no entanto, não são uma novidade para a referida organização multilateral e a acompanham desde sua fundação, em 1946 - contudo, ganharam forças após a pandemia da gripe H1N1, no ano de 2009 (ABEYSINGHE, 2019).

Nessa ocasião, a OMS viu-se alvo de uma série de críticas que encontraram vozes e ouvidos até no meio acadêmico e que alegavam que a entidade estava superada, superpolitizada, inoperante e que se tornara palco para os mais diversos tipos de conflito de interesses, falhando, inclusive, na gestão da crise gerada por aquela pandemia (VENTURA; PEREZ, 2014). KamradtScott (2018) relembra que essas críticas também vieram à tona quando da eclosão do surto do vírus Ebola, ocorrido na África Ocidental, em 2014. Por conta de uma série de erros de avaliação derivados de fatores estruturais, culturais, políticos e epidemiológicos, a OMS foi acusada de cometer diversos equívocos no modo de conduzir a crise derivada do maior surto dessa doença no mundo.

No caso da Covid-19, não poderia ser diferente. Sua atuação tem recebido muitas críticas com origens nos mais diversos segmentos da sociedade mundial, sendo as mais intensas e ferinas advindas da sede do governo federal dos Estados Unidos da América - que inclusive anunciaram a retirada do apoio financeiro.

Para Abeysinghe (2019), o cerne dos problemas enfrentados pela OMS no combate a epidemias reside no conflito existente na delimitação dos papéis exercidos tanto pela própria entidade quanto pelos estados nacionais que lhes são membros. Esse caráter ambíguo causa confusões a respeito das fronteiras de atuações de cada um desses países membros e a própria OMS.

Ainda que o Regulamento Sanitário Internacional (WHO, 2005a) atribua à OMS o comprometimento com ações de coordenação superveniente e de fornecimento de informação, enquanto imputa aos países membros as atividades de gestão das crises no âmbito de suas 
fronteiras, o avanço da integração entre as economias e a redução da intervenção estatal nas relações sociais de produção têm fragilizado essa esquematização administrativa, abrindo espaços para as mais diversas formas de contradições (ABEYSINGHE, 2019).

Durante a crise sanitária causada pela Covid-19, o mais contundente crítico da OMS é o Presidente dos EUA, Donald Trump. O fulcro de suas declarações está numa alegada demora da organização em responder à referida crise, além de acusá-la de estar demasiadamente "centrada na China". Na ocasião, o referido mandatário a ameaçou com a redução dos repasses do seu país como forma de pressão (WAMSLEY, 2020), vindo posteriormente a concretizar tal prenúncio ${ }^{8}$. Com relação à demora, é evidente que a OMS perdeu prazos importantes.

Entretanto, essa não é uma novidade no embate entre os USA e a entidade multilateral. Ainda na década de 1980, a administração do Presidente Ronald Reagan - 1981 a 1989 - liderou as nações industrializadas num congelamento real dos recursos destinados à OMS como reação a uma dita excessiva influência dos países periféricos (VENTURA; PEREZ, 2014). Chade (2020) entende a atitude da Casa Branca como um claro gesto de que os EUA não vão aceitar os desígnios da agência como força condutora de suas decisões, durante a pandemia de Covid-19. Ainda ressalta que isso seria reflexo do enfraquecimento e do desprestígio da OMS, tornando-a o alvo preferencial para governantes que buscam transferir responsabilidade e se eximir da culpa por possíveis danos que venham a ocorrer. Considera-se que, embora haja cometido erros na administração (como constatado neste artigo), os equívocos maiores foram cometidos pelas autoridades nacionais que, em certa medida, tentam transferir para a responsabilidade exclusiva da OMS suas incapacidades de resolver os problemas nacionais. Valécio (2020) reporta que tal conduta tem por pano de fundo as atuais disputas diplomáticas/comerciais entre os EUA e a China. Registre-se que esse anúncio, obviamente, foi criticado por Pequim, no que foi seguido por tradicionais aliados europeus dos norte-americanos e pelo secretário-geral da ONU, o exprimeiro-ministro português, António Guterres. Por sua vez, Hernandez (2020) mostra que o presidente americano não está só e que muitas críticas feitas à OMS, desde a aparição da Covid19, referem-se a uma possível leniência com aquilo que é interpretado por muitos como equívocos do governo da República Popular da China e com a demora em se pronunciar sobre o estado de pandemia da nova doença ${ }^{9}$.

\footnotetext{
8 O repasse americano de US $\$ 650$ milhões representa cerca de $11,13 \%$ de um orçamento anual de US $\$ 5,840$ bilhões. Registre-se que essa verba americana é (era) vinculada a programas definidos pela Casa Branca, com especial atenção para as doenças transmissíveis, como a malária e tuberculose e a erradicação da poliomielite.

${ }^{9}$ Este caso chinês é emblemático porque o médico Li Wenliang chegou a ser repreendido pela polícia de Wuhan por alertar sobre o problema na altura de dezembro de 2019; além da punição policial, também foi punido pela Covid-19 que lhe roubou a vida quatro meses após a sua denúncia. Este problema será abordado com mais profundidade no segundo artigo desta trilogia.
} 
A OMS tem respondido a essas críticas alegando que, a despeito de todas as suas limitações, ela tem envidado esforços para minimizar os efeitos da pandemia e tem promovido ações em quatro linhas de intervenção principais: superveniência de notificação e monitoramento, apoio à preparação local e capacidade de intervenção, promoção de pesquisa e desenvolvimento e combate à "Infodemia" (MULLEN, 2020).

Conforme ainda sumariza Mullen (2020), a organização buscou: manter os Estadosmembros informados sobre o cenário geral da doença; fornecer recursos para as nações mais desassistidas (de treinamento a infraestrutura de saúde); atuar como órgão coordenador na coleta de informações, no estabelecimento de áreas prioritárias para pesquisa e na disseminação de descobertas para o público em geral; além de ostensivamente combater surtos de notícias falsas e de desinformação por meio da constante atualização de dados sobre a pandemia. Por se tratar de medidas mais no campo da concepção, pouco se observa erros; porém, os mesmos aparecem com mais evidência quando da implantação dessas decisões, dimensão que responde pela capacidade de gerenciamento.

Nesse contexto, o Diretor-Geral da entidade, o Sr. Tedros Adhanom Ghebreyesus, tem se esforçado para desviar-se das críticas argumentando que não se pode politizar a pandemia e que este não é o momento para desvios e que o foco deve ser o combate ao novo coronavírus (UN NEWS, 2020).

Após esse painel, ficou claro que a Covid-19 pôs a OMS numa encruzilhada histórica, em que emerge o conflito de perspectivas de Administração Política da Saúde Global. Nessa aresta, a coordenação conjunta conflita com a condução nacional das ações de promoção do bem-estar psico-físico-biológico-material (econômico) das pessoas.

\section{Considerações finais}

Pelo exposto, parece não haver mais dúvida de que os danos causados pelo temível vírus da Covid-19 estão ficando maiores ainda devido aos erros cometidos pela OMS e também pelos governos nacionais. Muitos desses equívocos no campo da administração revelam-se grosseiros, especialmente no que se refere à identificação da força da sua zoonose, da fragilidade científica da sua farmacologia ou mesmo das deficiências estruturais da sua clínica médica.

Essas falhas administrativas não estão sendo sistematizadas com o devido rigor científico e muito menos seus custos estão sendo dimensionados. Decerto que os erros mais graves ganham evidências, mesmo assim, sempre terminam perdendo status quando se faz uma avaliação 
geral do evento pandêmico - prevalecendo, ao final, as preocupações com as partes relacionadas com a zoonose, a farmacologia e a clínica médica. Porém, não é possível considerar menos importante na contabilidade dos custos produzidos pelo novo Coronavírus aqueles erros decorrentes da má administração política e da administração profissional que estão sendo cometidos pelos diferentes governos ${ }^{10}-$ particularmente o chinês, o sueco, o inglês, o italiano, o norte americano e, sobretudo, o governo federal brasileiro.

No caso da OMS, fica patente que na partida das medidas pertinentes houve um erro que não poderia ter sido cometido em casos de tamanha gravidade como o que estamos vivendo com a pandemia decorrente da Covid-19. Conforme destacado no texto, houve um descompasso temporal entre o RSI e o CE para declarar Public Health Emergency of International Concern, alegando que os dados disponíveis eram insuficientes para a indicação de intervenção pertinente. Será que foi discutida à exaustão o cálculo de qual seria o risco/custo maior se se declarasse logo e nada acontecesse de mais grave ou não se declarasse logo a emergência e o fato acontecesse, da forma que aconteceu, produzindo essa hecatombe? Refletir sobre esse fato é essencial pois é aí que reside a essência elevada do que denominamos de Administração Política.

Decerto que esses erros decorrem de duas razões fundamentais: (a) do fato de os nossos administradores políticos desconhecerem totalmente os conteúdos administrativos pertinentes aos processos de concepção e execução dos nossos propósitos; e (b) não menos relevante, também pelo fato de os administradores profissionais - prepostos e executores das demandas/interesses dos administradores políticos - acharem que o ato de administrar (que significa conduzir um projeto para algum lugar ou alguma finalidade) está circunscrito ao arcabouço jurídico-institucional do que está sendo necessário fazer; enfim, do que é escolhido para ser feito.

No caso da pandemia da Covid-19, imaginar que o problema está resolvido com as decisões e firmar para a construção de novos hospitais, ampliação das enfermarias existentes, para a contratação de novos profissionais da saúde ou, ainda, para a simples liberação orçamentária de bilhões ou mesmo de trilhões de dólares, é cometer um erro fatal para solucionar a crise sanitária e encaminhar saídas socioeconômicas sustentáveis.

10 Registrem-se as honrosas exceções e a administração da pandemia até realizada pelo governo da Nova Zelândia para ser o caso mais notório. 
Depois da formalização dessas decisões, há ainda o longo e o mais difícil caminho da execução - que se expressa no gerenciamento das ações que levará à conclusão do processo: as unidades de saúde efetivamente prontas e entregues para o tratamento e cura do paciente enfermo ou o dinheiro chegando às famílias para continuarem suas vidas ou às empresas para se manterem ativas, garantindo os níveis de atividades.

Sendo assim, para que algo que desejamos possa dar certo não basta uma boa concepção do arcabouço jurídico-institucional do que é necessário fazer; é preciso que na execução desse projeto os caminhos inicialmente concebidos estejam sempre sendo refeitos, até se chegar ao ponto desejado com um menor custo individual e/ou social possível. Para que ocorra da forma mais desejável possível, é preciso que nunca seja perdida de vista a finalidade daquela ação que fora concebida e que se encontra em execução. É nisso que se encontra o sentido e importância vital na concepção (gestão) e execução (gerência) dos processos sociais - particularmente aqueles direta ou diretamente relacionados com a produção e a distribuição - enfim, com a vida e o bemestar social como modo de convivência permanente.

Esperamos que este desiderato fique melhor demonstrado quando das análises dos casos de regiões e países específicos, que serão objeto dos dois próximos artigos que completam esta trilogia: o bloco onde estão os países desenvolvidos, Estados Unidos, Europa, Japão e China; e o outro bloco restrito ao caso brasileiro, que possui uma singularidade em razão dos erros propositais que estão sendo cometidos, particularmente pelas autoridades que lideram o governo federal.

\section{Referências}

ABEYSINGHE, Sudeepa. Global health governance and pandemics: uncertainty and institutionaldecision-making. In: BJØRKDAHL, Kristian; CARLSEN, Benedict.

Pandemics, publics and politics: staging responses to public health crisis. Cingapura:

Palgrave/Macmillan, 2019, cap. 2, p. 11-28. https://doi.org/10.1007/978-981-13-2802-2.

Acesso em: 25 de maio de 2020. 
BIRD, Brian H.; MAZET, Jonna A. K. Detection of emerging zoonotic pathogens: an integrate done health approach. Annual Review of Animal Biosciences, Davis, v. 6, p. 121 139, 2018. https://doi.org/10.1146/annurev-animal-030117-014628. Acesso em: 18 de maio de 2020 .

CHADE, J. Ao cortar verba para OMS, Trump transfere culpa por mortes para alvo fácil. Notícias UOL, abr 2020. Colunas. Disponível em: https:// noticias.uol.com.br/colunas/jamil-chade/2020/04/15/ao-cortar-verba-para-omstrump-transfere-culpa-por-mortes-para-alvo-facil.htm. Acesso em: 29 de abril de 2020.

HERNANDEZ, J. C. Trump slammed the W.H.O. over Coronavirus. He's not alone. The New York Times, abr 2020. The coronavirus Outbreak. Disponível em: https://www.nytimes.com/2020/04/08/world/asia/trump-who-coronavirus-china.html. Acesso em: 29 de abril de 2020.

KAMRADT-SCOT'T, A. The Legal Basis for the WHO’s Global Health Security Mandate and Authority. In: KAMRADT-SCOTT, A. Managing Global Health Security. London: Palgrave Macmillan, 2015. cap. 1, p. 21-43. https://doi.org/10.1057/9781137520166_2. Acesso em: 29 de maio de 2020.

KAMRADT-SCOTT, A. What Went Wrong? The World Health Organization from Swine Flu to Ebola. In: KRUCK, A.; OPPERMANN, K.; SPENCER; A. (eds) Political Mistakes and Policy Failures in International Relations. Cham: Palgrave Macmillan. 2018. p. 193215. https://doi.org/10.1007/978-3-319-68173-3_9. Acesso em: 29 de maio de 2020.

LANA, R.; COELHO, F. C.; GOMES, F. C. Ferreira da Costa; CRUZ, O. G.; BASTOS, L. S.; VILLELA, D. A. M.; CODEÇO, C. T. Emergência do novo coronavírus (SARS-CoV-2) e o papel de uma vigilância nacional em saúde oportuna e efetiva. Cadernos de Saúde 
Pública, Rio de Janeiro, v. 36, n. 3, e00019620, 2020. https://doi.org/10.1590/0102311x00019620. Acesso em: 31 de maio de 2020.

MULLEN, L. How has the WHO responded to the Covid-19 pandemic? IPI Global Observatory, abr. 2020. Disponível em: https://theglobalobservatory.org/2020/04/howhas-who-responded-to-covid-19-pandemic/. Acesso em: 30 de maio de 2020.

Pandemics. Briefing European Parliament. European Union. 2020.

https://www.europarl.europa.eu/RegData/etudes/BRIE/2020/646195/EPRS_BRI(2020)64 6195_EN.pdf. Acesso em: 25 de maio de 2020.

PIKE, Brian L.; SAYLORS, Karen E.; FAIR, Joseph N.; LEBRETON, Matthew; TAMOUFE, Ubald; DJOKO, Cyrille F.; RIMOIN, Anne W.; WOLFE; Nathan D. The Origin and Prevention of Pandemics. ClinInfect Diseases, Oxford, v. 50, n. 12, p. 16361640, 2010. doi:10.1086/652860. Acesso em: 17 de maio de 2020.

QIU, W.; RUTHERFORD, Shannon.; MAO, A.; CHU, Cordia. The pandemic and its impacts. Healthy, Culture and Society, Pittsburgh, v. 9, n.10, p. 1-11, 2017. DOI 10.5195/hcs.2017.221. Acesso em: 18 de maio de 2020.

SANDS, Peter (Org.). From panic and neglect to investing in healty: financing pandemic prepared ness at a national level. Washington: International WorkingGroup on FinancingPreparedness (IWG)/World Bank.2017.

UN - United Nations. Policy brief: the impact of Covid-19 in children. Nova Iorque. 2020. Disponível em: https://unsdg.un.org/sites/default/files/202004/160420_Covid_Children_Policy_Brief.pdf. Acesso em: 27 de maio de 2020. 
UN NEWS. No need to politicize COVID-19: UN health agency chief. Nova Iorque: UN News. 2020. https://news.un.org/en/story/2020/04/1061392. Acesso em: 30 de maio de 2020.

VALÉCIO, M. OMS no fogo cruzado entre EUA e China. Instituto de Ciência, Tecnologia e Qualidade - ICQT. abr. 2020. Política Farmacêutica. Disponível em: https://www.ictq.com.br/politica-farmaceutica/1408-oms-no-fogo-cruzado-entre-eua-echina. Acesso em: 31 de maio de 2020.

VENTURA, Deisy; PEREZ, F. A. Crise e reforma da Organização Mundial de Saúde. Lua Nova, São Paulo, n. 92, p. 45-77, 2014.

WAMSLEY, L. Trump criticizes WHO and threatens to pull U.S. funding. NPR, abr. 2020. Corona vírus live up dates. Disponível em: https://www.npr.org/sections/coronavirus-liveupdates/2020/04/07/829244345/trump-criticizes-who-and-threatens-to-pull-u-s-funding. Acesso em: 29 de maio de 2020.

WHA72.1 - Seventy-second World Health Assembly. Program me budget 2020-2021: Agenda item 11.1. Genebra: World Health Assembly (WHA), 2019. Disponível em: https://www.who.int/about/finances-accountability/funding/A72_R1-en.pdf?ua=1. Acesso em: 29 de maio de 2020.

WHO - World Health Organization. International health regulations. 3a ed. Genebra: World Health Organization (WHO), 2005a. 
WHO - World Health Organization. Checklist for Influenza Pandemic Prepared ness

Planning. Genebra: World Health Organization (WHO), 2005b.

WHO - World Health Organization. WHO statement on novel coronavirus in Thailand. Genebra, jan. 2020b. Disponível em https://www.who.int/news-room/detail/13-01-2020who-statement-on-novel-coronavirus-in-thailand. Acesso em: 28 de maio de 2020.

WHO - World Health Organization. Novel Coronavirus (2019-nCov): Situation report 10. Genebra, jan. 2020c. Disponível em: https://www.who.int/docs/defaultsource/coronaviruse/situation-reports/20200130-sitrep-10-ncov.pdf?sfvrsn=d0b2e480_2. Acesso em: 29 de maio de 2020.

WHO - World Health Organization. WHO Timeline - Covid 19. Genebra, abr. 2020c. Disponível em: https://www.who.int/news-room/detail/27-04-2020-who-timeline---covid19. Acesso em: 29 de maio de 2020.

WHO - World Health Organization. Pneumonia of unknow case - China - Diseases out break news. Genebra, jan. 2020a. Disponível em: https://www.who.int/csr/don/05-january2020-pneumonia-of-unkown-cause-china/en/. Acesso em: 17 de maio de 2020.

WHO - World Health Organization. Guidance note on the role of Cash and Voucher Assistance to reduce financial barriers in the response to the COVID-19 pandemic, in countries targeted by the Global Humanitarian Response Plan COVID-19. Geneva: World Health Organization and Global Health Cluster Cash Task Team, 2020d. Disponível em: https://www.who.int/health-cluster/about/work/task-teams/Guidance-note-CVACOVID.pdf?ua=1. Acesso em: 27 de maio de 2020. 
WORLDOMETER. Covid-19 Coronavirus pandemic. 2020. Disponível em:

https://www.worldometers.info/coronavirus/. Acesso em: 29 de maio de 2020.

Recebido em: junbo de 2020

Aprovado em: julbo de 2020 